\title{
Construção de paisagem, espaço e lugar na várzea do rio Solimões-Amazonas
}

\section{Construction of landscape, space and place in river Solimões- Amazonas meadow}

Marcelo Souza Pereira - Mestre em Desenvolvimento Regional pela Universidade Federal do Amazonas, 2009; Economista da SUFRAMA, bolsista FAPEAM. E-mail: marcelo.pereira@suframa.gov.br

Antônio Carlos Witkeskei - Doutor em Sociologia pela Universidade Federal do Ceará, 2009; é professor do departamento de sociologia da Universidade Federal do Amazonas. E-mail: acwitkoski@uol. com.br

\section{Resumo}

O regime das águas do rio SolimõesAmazonas (enchente, cheia, vazante e seca) apresenta-nos paisagens que, a partir da presença humana, tornam-se espaços. Paisagem torna-se espaço a partir da dinâmica social, e pela experiência transforma-se em lugar. Homem e rio são agentes construtores deste fenômeno. As definições de "fixos" e "fluxos" são utilizadas para analisar as relações que determinam como, pelas águas e terras de trabalho da várzea, o espaço se transforma em lugar. O estudo evidencia os vários fluxos técnicos-informacionais e demais interferências sofridas pela organização produtiva local devido a "trocas" entre os lugares. Enfim, a dinâmica social, econômica e ambiental da várzea garante aos lugares e aos espaços um constante movimento, produzindo e reproduzindo o modo de vida e a organização social, espaços onde são satisfeitas as necessidades a partir da experiência do lugar.

\section{Palavra-chave}

Várzea. Paisagem. Espaço. Lugar. Rio. Amazônia.

\begin{abstract}
The seasonality of the river SolimõesAmazonas (inundation, flood, ebb tide and drought) it presents in the landscapes that become spaces starting from the human presence. Landscape becomes space starting from the social dynamics, and for the experience it becomes place. Man and river are building agents of this phenomenon. The definitions of "fixed" and "flows" they are used to analyze the relationships that determine as, for the waters and lands of work of the meadow, the space becomes place. The study evidences the several flows informationtechnical and other suffered interferences for the local productive organization due to the "changes" among the places. Finally, the dynamics social, economical and environmental of the meadow guarantees to the places and the spaces a constant movement, producing and reproducing the life way and the social organization, spaces where are satisfied the needs starting from the experience of the place.
\end{abstract}

\section{Keywords}

Meadow. Landscape. Space. Place. River. Amazonia. 


\section{INTRODUÇÃO}

A falta de oportunidade econômica e de liberdade social, segundo Tuan (1983, p. 69), faz o mundo dos isolados povoados rurais parecer estreito e limitado. Esta forma de perceber a realidade dos espaços rurais, aparentemente, deixa transparecer uma espécie de inferioridade. Mas, diante dos acontecimentos globais e da velocidade com que fluem as informações, dependendo de qual prisma se pretende observar, os "isolamentos" na Amazônia recebem outras conotações e talvez não seja uma assertiva verdadeira.

A várzea foi a primeira fronteira de expansão da colonização europeia na Amazônia, portanto, a primeira a sofrer intervenções doutras culturas, políticas e economias, influenciando sobremaneira as paisagens, os espaços, os lugares e as formas de vida dos habitantes. Estes habitantes, segundo Pereira (2011, p. 11), constituem a maior parte da população rural da Amazônia, herdando possivelmente a cultura e organização social dos povos indígenas.

Em meio às discussões acerca da paisagem, do espaço e do lugar, relacionados à vivência humana nos diversos ambientes, o estudo evidencia a experiência do camponês ribeirinho na várzea do rio Solimões-Amazonas, uma dinâmica que depende do regime das águas ${ }^{1}$, que cria uma organização em torno do calendário natural das águas, possibilitando entender a construção de paisagens, espaço e lugar na várzea do rio Solimões-Amazonas.

A partir dos fixos e fluxos, de Milton Santos (1988), o estudo analisa as relações que determinam o lugar, as interferências do global no local e do local no global, assim como o espaço se torna o lugar na várzea das águas de trabalho. Os espaços de águas e as terras molhadas da várzea amazônica são a representação de um mundo de realizações para seu habitante, o espaço das relações sociais, o lugar da relação íntima com a natureza.

\section{O QUE É A VÁRZEA?}

O Conselho Nacional do Meio Ambiente (CONAMA), no Artigo 2", "c" da resolução $n^{\circ}$ 04, de 18 de setembro de 1985, define a várzea como o leito maior sazonal, que significa nos termos do documento: "calha alargada ou maior de um rio, ocupada nos períodos anuais de cheia”. Entretanto, Vieira (2000 apud

\footnotetext{
1 A enchente é caracterizada pela subida das águas; a cheia, pelo nível máximo das águas; a vazante, pela descida das águas; e a seca, pelo mais baixo nível das águas. Estas são consideradas pelo autor como as "estações climáticas" do ecossistema de várzea, resultado da falta de sincronização entre o regime fluvial e pluvial (PEREIRA, 2011, p. 15).
} 
SURGIK, 2005, p. 17), afirma que a várzea se enquadra no conceito de solos aluviais descritos no Artigo $16^{\circ}$ do Código de Águas brasileiro, ou seja,

[...] os acréscimos que sucessiva e imperceptivelmente se formarem para a parte do mar e das correntes, aquém do ponto a que chega o preamar médio, ou do ponto médio das enchentes ordinárias, bem como a parte do álveo que se descobrir pelo afastamento das águas [grifo nosso].

O mesmo código, no parágrafo $2^{\circ}$ do Artigo $11^{\circ}$, define que "será tolerado o uso desses terrenos pelos ribeirinhos, principalmente os pequenos proprietários, que os cultivem, sempre que o mesmo não colidir por qualquer forma com o interesse público".

O Instituto Brasileiro do Meio Ambiente e dos Recursos Naturais Renováveis (IBAMA, 2005, p. 9), por meio do Projeto Manejo dos Recursos Naturais da Várzea (ProVárzea), definiu a várzea como um lugar onde há ligação direta entre água e terra, em que numa época do ano o solo fica exposto, ou seja, seco e, noutra época, fica inundado.

Este ambiente ocorre ao longo dos rios com cheias e vazantes, normalmente habitados por agricultores, pescadores, extrativistas e criadores de gado, que utilizam a várzea na Amazônia como “[...] o principal lugar de atividades de subsistência da população ribeirinha [...] (desempenhando) importante papel na vida social e econômica" (PIRES, 2011, p. 99).

\section{HOMEM E RIO: CONSTRUTORES DE ESPAÇOS E PAISAGENS NA VÁRZEA}

A Amazônia, revelada ao mundo no século XVI, a partir das expedições que adentraram o continente pelo "grande rio" e seus afluentes, é relatada de forma romântica - exaltando as imaginações e fantasias do primeiro contato pelos europeus que se autodenominaram "conquistadores", como se as terras e os povos recém-descobertos não possuíssem um passado, uma história, uma evolução social no tempo.

O relato inicial dos expedicionários foi reflexo da paisagem que a visão detectou. A paisagem é, portanto, tudo o que nossa visão alcança, o domínio do visível que toma escalas diferentes dependendo da percepção, isto é, cada um percebe as coisas materiais de forma diferenciada (SANTOS, 1988, p. 61-62). Certamente, se aqueles navegantes conhecessem a cultura e a organização social dos povos que habitavam os espaços desbravados, perceberiam uma paisagem distinta.

Grande rio foi a denominação que Frei Gaspar de Carvajal, cronista da expedição de Francisco Orellana, utilizou em referência ao rio Solimões-Amazonas (GIUCCI, 1992). 
Milton Santos (1988) afirma existir paisagem artificial e paisagem natural, sendo a primeira transformada pelo homem e a segunda aquela ainda não mudada pelo esforço humano, o que o fez concluir que a paisagem é sempre heterogênea, pois é um conjunto de formas naturais e artificiais, onde a vida em sociedade é a responsável pela multiplicidade de formas, que se distanciam de um mundo natural e direciona para um mundo artificial.

O trabalho mecânico das águas do rio Amazonas transforma e constrói paisagens naturais. Ao longo dos séculos soterrou braços de afluentes, estreitou ou alargou canais, comprimiu florestas, aumentou terras, alterou o traçado do rio, criou obstáculos pelo depósito de seus sedimentos, revelou ilhas depois das cheias ou atalhos pelos furos, erodiu terras e expulsou habitantes de suas margens. Enfim, o rio é um verdadeiro construtor de paisagens nas várzeas amazônicas.

Pereira (2011) aponta diversas unidades paisagísticas criadas a partir do movimento de subida e descida das águas do rio Solimões-Amazonas, no trecho Manaus-Coari, no estado do Amazonas, destacando-se: praias, ilhas, baixios, aningais, lagos temporários, diques, ressacas, restingas, canais etc. Enfim, a ação do curso das águas renova e altera as paisagens, que podem ser percebidas de maneiras diversas em períodos de cheias ou de secas. Tocantins (1973, p. 110) relata sobre esta ação de construção e modificação de paisagens:

O ciclo de enchente e vazante, comandado pela mecânica das águas, repetese várias vezes durante o inverno, até que por fim o rio estagna numa horizontalidade mínima, ao entrar a época da estiagem. E surgem no leito quase à mostra coroas de areia, paus enterrados no álveo, acidentando o caminho fluvial, bloqueando os transportes.

Por outro lado, a presença do homem à margem do rio constrói paisagens artificiais, na medida em que engenha objetos que possibilitam a adaptação às alternâncias das fases terrestres e aquáticas do ambiente, por exemplo, os canteiros suspensos (jirau), utilizados pelos agricultores para o cultivo de hortaliças nos períodos de cheia e enchente; a palafita, moradia preparada para receber a subida das águas e, quando necessário, levantar o seu assoalho (piso); o flutuante, uma construção típica das margens dos rios na Amazônia, que garante ao habitante permanecer em sua propriedade ou até mesmo migrar para outras localidades durante a cheia; a maromba, uma engenharia cabocla, que consiste no confinamento do gado em um pequeno curral flutuante de madeira em períodos de cheias, quando falta solo para pastagem.

Em Homens anfíbios, Fraxe (2000) revela-nos a dinâmica da vida adaptativa do camponês das várzeas do rio Solimões-Amazonas, que desenvolve estratégias para conciliar os ambientes de terra e água ao seu cotidiano, isto é, concebem 
uma dinâmica social à paisagem da várzea, transformando-a em espaço, habitado por sujeitos sociais que, por meio do trabalho e apoiados por suas capacidades inventivas, adaptam espécies vegetais utilizando-se do saber tradicional, demonstrando a racionalidade econômica dos sujeitos sociais em suas atividades de trabalho. Para Fraxe (2000, p.137), "O homem anfíbio é a personificação da forma de 'produção simples de mercadorias'. Nesse tipo de produção, ele detém a propriedade da terra, da água e dos instrumentos de trabalho, com os quais desenvolve suas atividades".

A capacidade adaptativa do homem possibilitou a ocupação humana da várzea como um espaço de uso e de moradia. Aliás, este modo de vida não é uma construção atual, mas um conjunto de heranças dos "pedaços de tempos históricos representativos das diversas maneiras de produzir as coisas, de construir o espaço" (SANTOS, 1988, p. 68). Os relatos dos primeiros registros da calha do rio Amazonas e seus afluentes comprovam a existência de imensos povoados indígenas, bem como a harmonia existente entre os índios e a natureza, que retiravam da floresta e dos rios os alimentos que ofereciam aos homens da expedição de Orellana (1939-1942), vencidos pelo cansaço, pela fome e que não entendiam de onde vinha tanta fartura, quando eles próprios tinham que lutar primeiramente pelo sustento alimentício (GIUCCI, 1992, p. 23). Neste momento a produtividade da várzea era claramente revelada.

A várzea sem a presença humana é apenas uma paisagem. Todavia, a vida existente dá à várzea o status de "espaço". O espaço não é paisagem, já dizia Santos (1988). O primeiro é o conjunto de objetos naturais, sociais e a vida que os anima, percebido por sua dinâmica, ou seja, a sociedade em movimento. Enquanto a segunda revela uma percepção da visão estática. O espaço é a relação da realidade da natureza e da sociedade mediatizada pelo trabalho, resultado do casamento da sociedade com a paisagem, enquanto que a paisagem é a materialização de um instante da sociedade, construída e modificada por diferentes momentos durante a história, pelo conjunto de técnicas de trabalho humano ou ações da natureza.

O rio Solimões-Amazonas e o homem são, sem dúvida, os maiores construtores de paisagens e espaços na Amazônia. O rio e o regime sazonal de suas águas regulam o calendário agrícola e moldam os ambientes ocupados pelos habitantes às suas margens e de seus afluentes, possibilitando - pelas propriedades do solo fertilizado por sedimentos com alto teor de nutrientes - a manutenção de um modo de vida ímpar, baseado na agricultura altamente produtiva de ciclo curto, garantindo a ocupação e uso dos solos e das águas (os espaço), ao mesmo tempo em que modificam a paisagem. 


\section{A CONSTRUÇÃO DO LUGAR NA VÁRZEA}

Para compreendermos quaisquer ambientes, primeiramente precisamos ter o contato inicial, mesmo que somente pela impressão visual e de forma estática (a paisagem). Mas, com o transcurso do contato conhecemos as características, entendemos o funcionamento, percebemos as diversas formas de organização social, cultural, política, econômica, etc -, o movimento, a totalidade ${ }^{3}$ (o espaço). Entretanto, tendemos a vivenciar o espaço, apreendendo-o intimamente, ao passo que desenvolvemos sentimentos particulares, neste momento, a paisagem que se transfigurou em espaço passa a ser "lugar".

Tuan (1983) defende que espaço e lugar são elementos do meio ambiente intimamente relacionados, ideias que não podem ser definidas uma sem a outra. Para o autor, o espaço é mais abstrato que o lugar e, apesar de fundirem-se frequentemente, ou seja, o que inicialmente é espaço indiferenciado transformase em lugar, na medida em que dotamos o espaço de valor e o conhecemos melhor. Explicando de uma forma mais didática, o autor entende que no lugar as necessidades biológicas humanas são satisfeitas, tais como: comer, beber, descansar, procriar, trabalhar. Enfim, no lugar as ações humanas se concretizam no cotidiano e na familiaridade, pelas maneiras de "aprender com a própria vivência" ou simplesmente com a "experiência".

Outra forma de perceber o lugar é apresentada por Santos (2009, p. 322; 339), quando o define como "o teatro insubstituível das paixões humanas, responsáveis, através da ação comunicativa, pelas mais diversas manifestações da espontaneidade e da criatividade". Contudo, o autor entende que no lugar (no local) as manifestações são influenciadas por eventos mundiais (o global), impondo ao local a racionalidade do global. Nos lugares, as ações se concretizam, isto é, no lugar a existência se dá. Esta complexa relação local e global, lugar e mundo, levou o autor a afirmar: "Cada lugar é, ao mesmo tempo, objeto de uma razão global e de uma razão local, convivendo dialeticamente".

Os espaços amazônicos sempre estiveram mediados por forças hegemônicas capitalistas desde que foram revelados ao velho mundo. A este respeito, Silva (2000, p. 2 apud WITKOSKI, 2010, p. 22) afirma que "a Amazônia pode ser vista como uma formação econômico-social produzida, desde a sua origem, pela dinâmica do capitalismo e, portanto, sujeita aos processos de expansão e crise do capital". Nesta assertiva podemos perceber, analogamente aos preceitos de Santos (2009),

3 A totalidade é o conjunto de todas as coisas e todos os homens em sua realidade, isto é, em suas relações, em seu movimento. [...] é o 'conjunto absoluto das partes em relação mútua'. [...] que está sempre se desfazendo para voltar a se fazer”, o que caracteriza o movimento do espaço (SANTOS, 2009, p. 116-117). 
como a racionalidade global capitalista influenciou na construção dos diversos lugares amazônicos.

Como cientistas, podemos afirmar que conhecemos a dinâmica dos rios na várzea amazônica, defendendo conceitos e inclusive demonstrando propriedades e características sociais, econômicas e até mesmo físico-químicas do solo e da água, sem nunca termos pisado nestes espaços ou navegado pelos rios. O sentimento construído é de interesse acadêmico e a experiência é a pesquisa, ancorada na relação das normas de investigação, é o que Tuan (1983) chama de criação de "espaços abstratos", por meio da materialização dos sentimentos, imagens e pensamentos. Diferentemente, quando o pesquisador vai a campo, convivendo com as comunidades na labuta diária e compreendendo a organização social, econômica, política e cultural in loco, mesmo assim a experiência não é total, mas o que era espaço começa a ser percebido como lugar: da pesquisa, do pescador, do agricultor, do extrativista, da dona de casa, do canoeiro, do catraieiro etc.

Os habitantes das várzeas do rio Solimões-Amazonas alimentam sentimentos pelo lugar, seus locus de morada e de trabalho. A terra (na vazante e seca) e a água (na enchente e cheia) são experienciadas pelo camponês de formas diversas. A agricultura, a pesca ou o extrativismo - suas atividades de trabalho, dependendo do regime das águas -, permite a este trabalhador polivalente a concreção de valor ao seu lugar. Nestes "lugares", por mais que os habitantes sofram pressões dos hegemonismos capitalistas, impostos pelas redes de comunicações diversas e constantes com os centros urbanos, a racionalidade cabocla faz valer a solidariedade, a comunhão, os costumes, o compadrio, bem como as águas do rio tornam-se o calendário do lugar, informando quando plantar, quando colher, quando trabalhar, quando descansar, enfim, sua organização social é determinada pela natureza.

Collyer (1999, p. 166) afirma que:

A água exercita uma superioridade irrecorrível, sendo ela a grande verdade da natureza amazônica. Estabelece-se, portanto, o poder social dos rios, ao qual o homem se submete [...] À medida que as águas sobem, o homem suspende o assoalho de sua casa espremendo-se com a sua família entre ele e o telhado [...] Quando as águas baixam ele retorna a sua vida normal. Replanta sua roça caseira, solta suas galinhas no terreiro e recomeça a vida, na certeza de que a terra adubada pelas águas lhe garantirá boa colheita.

Pelo trabalho, seja na água ou na terra, o homem da várzea exercita a "experiência" e transforma espaço em lugar, criando identidade com o ambiente: plantando, pescando, navegando ou coletando produtos que garantam sua subsistência e de sua família. Estes construtores e inventores empíricos extraem significados do ambiente por meio de técnicas particulares que atendem 
necessidades ou, segundo Tuan (1983), atendem condições para a "sobrevivência biológica". O ambiente anfíbio apresentado por Fraxe (2000), que dificulta a vida no ambiente de várzea, é o lugar onde o camponês demonstra toda a capacidade de adequar-se ao espaço de terras e águas, dele retirando os meios para sobreviver e morar.

A maneira de perceber a realidade da vida na várzea por Fraxe (2000) é, analogamente, corroborada por Tuan (1983, p. 89-90), quando demonstra a adaptação do esquimó ao seu ambiente:

Em uma neblina fechada, o navegante do Ártico estabelece sua posição no mar pelo som das ondas quebrando na terra e pela observação do vento. A natureza pode ser hostil e enigmática, porém o homem aprende a compreendê-la - extrair-lhe significado - quando isto é necessário para a sua sobrevivência [...] Os esquimós se adaptaram ao seu meio ambiente inóspito e se sentem relativamente aclimatados a ele.

A navegação é outra atividade, de trabalho ou de subsistência, que aponta a intimidade do homem com seus lugares. O morador dos rios, familiarizado com seu ambiente, o reconhece em quaisquer circunstâncias, seja no período da cheia ou da seca. Se um indivíduo forasteiro aventurar-se navegar pelos rios que adentram as terras no período da cheia, ou até mesmo a navegar a calha central e secundária do rio Solimões-Amazonas, deparar-se-á com caminhos totalmente diferentes daqueles que se apresentam nos períodos de seca, e certamente não terá a precisão necessária para decidir o caminho correto, exceto se possuir instrumentos que o guiem.

Diferentemente, sem quaisquer equipamentos, o caboclo-ribeirinho ${ }^{4} \mathrm{da}$ várzea toma sua canoa ou catraia e percorre instintivamente os caminhos e os cursos sinuosos dos rios, furos e canais, conhecendo exatamente quais os melhores lugares para a caça, os tipos de vegetação, o melhor ponto de pesca, tudo por meio de mapas mentais construídos a partir da experiência com o lugar. A navegação amplia as possibilidades, o barco aumenta o mundo do ribeirinho, torna-se uma extensão de seus poderes corporais, aumenta a liberdade e coloca-o em uma relação íntima com vastidão da natureza. Tocantins (1983, p. 82) compara a canoa ao cavalo para o ribeirinho.

4 A categoria "caboclo-ribeirinho" da várzea é uma categoria formulada por Fraxe (2004) a partir de outras duas categorias já existentes, o "caboclo" e o "ribeirinho", que designa o morador das margens dos rio Solimões-Amazonas e seus afluentes. Na verdade, a categoria formulada por Fraxe é uma categoria híbrida, já que alguns moradores se autointitulam caboclos e outros preferem ser chamados de ribeirinhos. De outra forma, Witkoski (2010) passa a denominar este sujeito social de camponês amazônico. 
A canoa supre o cavalo. O campo é a água do meândrico sistema hidrográfico. O caboclo mesmo batizou de montaria ao casco ligeiro que singra o dorso das águas, enveredando pelos rios, furos, igarapé e até por entre a floresta submersa [...].

Quem não experiencia o lugar, não pode relatar sobre ele. A familiaridade do morador com o seu lugar é demonstrado pela percepção das mudanças ocorridas ao longo dos anos, ou seja, assim como Santos (2009) afirmou que o espaço é "pedaços de tempos históricos", o lugar, como componente inseparável do espaço também apresenta mudanças ao longo do tempo, que são percebidas e relatadas por seus moradores, como foi o caso da Sra. Iracema, uma agricultora de 74 anos, residente na comunidade São Francisco da Costa da Terra Nova, no Careiro da Várzea/AM, entrevistada em 2001 por Fraxe (2004, p. 69-79), que discorreu sobre sua percepção sobre as mudanças ocorridas na comunidade em que vive, revelando a preocupação ambiental do morador da várzea:

Antigamente aqui tinha mais fartura, tinha mais peixe, tinham mais casas, as pessoas eram mais amigas, mais solidárias, muito mais do que são hoje. Nos terrenos não tinha nenhuma espécie de cerca ou até mesmo flores dividindo uma casa da outra. Só quem mais coloca pra dividir uma casa da outra, são esses homens que criam gado, [...] ninguém sabia o que era passar dificuldade aqui. [...] Hoje em dia a gente come do que tem, nessa época (junho/2001 - nível máximo que as águas atingiram) o peixe que melhor dá é bodó, assim mesmo na lama, sabe porque professora? Porque eles acabaram com o nosso lago. [...] Hoje, muitas vezes a gente tem que comprar, a gente come do comprado [...], a gente vive mais daquilo que se compra do que daquilo que a natureza pode dar.

Os vastos espaços de água que podem parecer desertos para os turistas que visitam as áreas alagadas e terras molhadas da várzea amazônica ou as belezas cênicas de sua paisagem são, para o morador e trabalhador do lugar, a representação do mundo de realizações, o espaço das relações sociais e o lugar da relação íntima com a vastidão da natureza - a sua moradia.

\section{FIXOS E FLUXOS NA ORGANIZAÇÃO SOCIAL DA VÁRZEA}

Em As conseqüencias da modernidade, Giddens (1990, p. 11) revela-nos que erroneamente as sociedades, por exemplo, a ocidental, vislumbram a história como uma continuidade, uma evolução que “"começa' com culturas pequenas, isoladas, de caçadores e coletores, movimenta-se através do desenvolvimento de comunidades agrícolas e pastoris e daí para a formação de estados agrários, culminando na 
emergência de sociedades modernas". A desconstrução desse enredo evolucionário ajudaria a elucidar a tarefa de analisar a modernidade. Mas, para desconstruir o evolucionismo outrora construído, Giddens (1990, p. 98) mostra que é preciso entender as relações entre o lugar e o mundo:

O local e o global, em outras palavras, tornaram-se inextricavelmente entrelaçados. Sentimentos de ligação íntima ou identificação com lugares ainda persistem. Mas eles mesmos estão desencaixados: não expressam apenas práticas e envolvimentos localmente baseados, mas se encontram também salpicados de influências muito mais distantes. Até a menor das lojas da vizinhança, por exemplo, pode muito bem obter suas mercadorias de todas as partes do mundo. A comunidade local não é um ambiente saturado de significados familiares, tidos como garantidos, mas em boa parte uma expressão localmente situada de relações distanciadas.

Possíveis explicações sobre a influência dos acontecimentos distantes no local e como estas influências e acontecimentos chegam e se instalam nas organizações sociais locais podem ser encontradas a partir das categorias fixos e fluxos, formulados por Santos (1988). Podemos entender os fixos como os instrumentos de trabalho e as forças produtivas locais, incluindo toda a massa dos habitantes que trabalham (homens, mulheres e crianças). Os fluxos são os movimentos, a circulação técnica ou informacional, as interrelações que surgem a partir dos fixos ou chegam até os fixos, por meio da fluidez (ou fluxo) das informações e das técnicas.

Visto desta forma, o espaço nunca é o mesmo, porque o lugar também não é. Ambos, espaço e lugar, podem particularmente possuir características superficialmente idênticas, mas a essência da organização social, econômica, cultural, política, etc. muda. Isto ocorre pelo fato da sociedade, que dá vida ao espaço pela dinâmica da experiência do local, estar sempre em movimento, metamorfoseando os espaços habitados, o que passa a impressão que a sociedade muda de pré-moderna para moderna, conforme recusado por Giddens (1990). O que ocorre são reflexos do embricamento da história passada (tradição e costumes, principalmente) e o movimento da reconstrução dos espaços, que segundo Santos (2009, p. 239), cada vez mais se tornam espaços "técnico-cientifico-informacionais" tendentes a atender "aos interesses dos atores hegemônicos da economia, da cultura e da política".

Na várzea - locus da ação dos sujeitos sociais (caboclo, ribeirinho, cabocloribeirinho, camponês) e das relações sociais -, podemos identificar os fixos: casas, roçado, inventos para a adaptação ao ambiente anfíbio (maromba, jirau, palafita, flutuantes, canoa, catraia etc.), que Santos (2009) chama de componente do "sistema de objetos" ou "natureza artificial". O conjunto desses objetos é oriundo do saber 
tradicional, ou seja, dos conhecimentos adquiridos pelo empirismo, a partir da experiência no lugar ou, de outra forma, reflexos de saberes trazidos de culturas ou organizações sociais distantes, que não são do lugar. Como esses saberes, culturas e práticas de organizações sociais distantes chegam até o lugar? Por meio dos fluxos, da fluidez informacional que Santos retrata em sua vasta biografia, e que estamos, analogamente, tentando ilustrar no ambiente de várzea.

As comunidades rurais da várzea amazônica são lugares onde os fluxos podem ser percebidos a partir do movimento do rio, das práticas culturais, da economia de subsistência, da organização social e política, etc. que imbricam costumes tradicionais com lampejos, cada vez mais presentes, de práticas ou técnicas oriundas das sociedades urbanas capitalistas. Fraxe (2004) apresentanos toda uma "re-significação" dos fluxos e fixos, em sua obra intitulada Cultura cabocla-ribeirinha. A autora demonstra como os costumes da Comunidade São Francisco, localizada no município do Careiro da Várzea/AM, entrelaçam-se ao meio urbano, principalmente no espaço do mercado municipal Adolpho Lisboa, em Manaus/AM, onde a comunidade realiza a comercialização da produção agrícola, particularmente ervas medicinais.

A atividade prevalecente no período da seca é a agricultura e na cheia passa a ser a pesca, apesar de ambas as atividades serem empregadas pelos trabalhadores ribeirinhos, tanto na cheia quanto na seca, combinando-as com a coleta extrativa. Segundo Witkoski (2010), a adaptabilidade aos ambientes de água e terra, confere ao camponês amazônico o trabalho simultâneo em terras, florestas e água. O caboclo-ribeirinho é agricultor, criador e extrator, sujeito social e possuidor de racionalidade econômica divergente da racionalidade hegemônica capitalista, mas que não deixa de ser impactada por esta. Ele é proprietário de capital social e intelectual, revelando seu conhecimento a partir de suas atividades laborais, seja em terra ou em água, o que o torna um agente social e econômico "multifuncional" e "polivalente".

Empresto novamente as palavras de Tuan (1983, p. 69), com que iniciamos a discussão deste estudo, quando afirma que "A falta de oportunidade na esfera econômica e de liberdade na esfera social fazem o mundo dos isolados povoados rurais parecer estreito e limitado". Falar de isolamento das comunidades rurais na Amazônia não é mais possível, na medida em que entendemos que o espaço e o lugar da várzea são permeados por variadas formas de relações sociais, econômicas, políticas e culturais, que se constroem e se reconstroem a partir de influências internas ou externas, o que possibilita a reprodução social, a construção da história camponesa e sua vida material. Percebamos que a assertiva é: "construção" da história a partir de reprodução social e não "evolução" da história! 
Segundo Marx (apud FRAXE, 2004, p. 252), produzir vida material é ter condições de viver (comer, beber, morar e vestir), ou seja, atender às suas necessidades para reproduzir-se e manter relações sociais, o que faz com que os homens vivam numa articulação determinada por um modo de produção, unido a um modo de cooperação, resultando no desenvolvimento das forças produtivas da sociedade. Quando se fala em relações sociais, estas não se limitam apenas ao lugar, mas se desenvolvem no espaço a partir dos diversos lugares, os diversos pontos que se comunicam como que em redes.

Esta noção nos leva a entender a divisão social do trabalho, que para Santos (2009): a) lugares diferentes atendem às diversas demandas de outros lugares, por meio da oferta de seus produtos; b) os mesmos lugares que ofertam produtos, também demandam outros tipos de produtos que não produzem; c) informações técnicas externas influenciam os modos de produção no local, ou seja, os fluxos alterando os fixos. As redes, segundo o autor, criam objetos e lugares que circulam, levam e trazem informação, denominados fluxos. Não basta produzir, é indispensável pôr a produção em movimento.

Witkoski (2010, p. 167), por meio de uma interpretação distinta da de Santos (2009), indica que podemos entender, a partir do trabalho, como a unidade de produção familiar camponesa produz e reproduz sua condição de existência, "um trabalho composto por objetos de produção (matéria-prima) produto natural ou semimanufaturado -, instrumentos de trabalho (ferramentas e máquinas etc.) e força de trabalho (essencialmente familiar)". Esta força de trabalho reflete a divisão social do trabalho ou divisão sexual do trabalho: crianças pescam (atividade para consumo interno do grupo familiar e considerada mais leve), pais e filhos mais velhos trabalham na agricultura, mulheres e filhas mais novas cuidam das atividades domésticas e da rocinha (uma roça menor para consumo interno da família, sem fins comerciais), mas todos são braços para a unidade produtiva familiar.

Então, a partir da noção de aparente "isolamento" de comunidades rurais, retratado por Tuan (1983); da produção da vida material segundo Marx apud Fraxe (2010); dos pressupostos cognitivos de Santos (2009), ao trabalhar a noção de rede e fluidez; da transculturalidade apresentada por Fraxe (2004), na comunidade São Francisco; e da organização racional do núcleo produtivo familiar demonstrado por Witkoski (2010), podemos afirmar que não existe isolamento nas comunidades de várzea do rio Solimões-Amazonas, pois os sujeitos sociais possuem uma organização social e produtiva que se interliga aos centros de consumo, na medida em que há fluidez de produtos e informações técnicas. 


\section{ALGUNS FIXOS E FLUXOS NA VÁRZEA AMAZONENSE}

As comunidades de várzea surgiram à margem do rio: por processos incentivados de migrações ou desdobramentos destas políticas, como foi o caso dos seringueiros, que após a derrocada da economia da borracha se viram obrigados a retornar para suas cidades ou direcionaram seus esforços para atividades agrícolas; por ocupações ilegais, motivadas pela expansão da fronteira agrícola; pelo déficit habitacional; pela miscigenação do homem branco com o índio. Enfim, populações de agricultores, pescadores e extrativistas se estabeleceram à margem do rio, instalando suas infraestruturas pessoais - os seus fixos -, passando a produzir alimentos para si e para os núcleos urbanos. Da mesma forma, recebem dos núcleos urbanos gêneros que atendam às suas necessidades, que não estão disponíveis em suas unidades de produção. Para Santos (1988), esta dinâmica é possível por meio da ação dos fluxos sobre os fixos.

O rio altera as paisagens, os espaços e os lugares a partir da mecânica aluvial. O que era um fixo na seca (a terra do cultivo) torna-se um fluxo na cheia (rotas, canais, atalhos de navegação), caminhos que são adaptados para o escoamento da produção e traslado dos habitantes. O movimento das águas possibilita o intercâmbio entre os diversos lugares nas "terras alagadas". O rio é a rota por onde fluem as informações e as pessoas, é o lugar onde o tempo acontece e se concretiza para seu habitante. Quando Nogueira (1999) afirma que o rio é um caminho que não precisa ser construído, que marcha, desliza e se move por si, sua assertiva traduz a dinâmica dos fluxos nas águas dos rios. O mesmo autor exemplifica como acontece o movimento social ribeirinho:

Os defuntos vão para as covas embarcados, embarcados vão os noivos, os padeiros, as procissões, os caçadores, os comerciantes, os trabalhadores, os eleitores, os namorados, os músicos. O rio é a rua. [...] muitas vezes se encarregam de pequenos, mas importantes serviços, como levar correspondências, dinheiro, remédios, e até pequenas mercadorias aos parentes e amigos que residam no itinerário percorrido, como alimentos, gelo, gasolina etc. (NOGUEIRA, 1999, p. 112-113).

Os instrumentos de labuta desses habitantes, suas casas, o templo religioso, a associação dos moradores, entre outras infraestruturas, como já relatamos, são os objetos "fixos". Cada fixo tem características diversas e sofrem influência direta dos fluxos. Para Santos (1988), fixos e fluxos interagem mutuamente. A comunidade em si é um fixo, mas o que lhe deu origem foram os processos sociais que chegam ao lugar a partir dos fluxos, isto é, a sociedade em movimento, a ação humana 
motivada pela economia, pela cultura, pela política e não uma sociedade evolutiva, criticada por Giddens (1990).

No período da seca a várzea é altamente produtiva. Homens (e também mulheres e crianças) trabalham sobre o solo (seu lugar e seu fixo) em busca do atendimento das respectivas necessidades, reproduzindo-se socialmente no lugar, por meio de uma típica e ímpar divisão social do trabalho - ou conforme Witkoski (2010), uma “divisão sexual do trabalho" camponês - que prima por atender às demandas alimentares de suas famílias e produzir excedentes para suprir a demanda alimentar de outros lugares, por exemplo, os centros urbanos onde normalmente se fixam os grupos dominantes (políticos e econômicos). Para Wolf apud Witkoski (2010, p. 160-161)

[...] Nas sociedades primitivas, os excedentes são trocados diretamente pelos grupos ou por seus membros; os camponeses, no entanto, são cultivadores rurais [criadores, extratores (produtos florestais, pesca e caça etc)] cujos excedentes são transferidos para as mãos de um grupo dominante, constituído pelos que governam, que utilizam para assegurar nível de vida, e para distribuir o restante entre grupos da sociedade que não cultivam a terra [não coletam, não caçam, não pescam], mas devem ser alimentados, dando em troca bens específicos e serviços.

O que motiva o trabalhador é a possibilidade de uma grande safra que garanta, primeiramente, os alimentos para o seu sustento e o atendimento das necessidades de sua família, e em segundo plano, mas não menos importante, produzir excedentes para comercializar. Para que a comercialização se concretize é necessário que condições de escoamento sejam criadas, além da existência de sujeitos dispostos a comprar o excedente, uma racionalidade aparentemente capitalista, mas que não é o centro da racionalidade camponesa, ou seja, o excedente de comercialização não é o objeto fim do varziano, pelo contrário, a sobrevivência e subsistência familiar é o cerne da organização econômica e social.

Fica claro que a produção de excedentes não reflete uma racionalidade capitalista, o que na perspectiva de Pereira (2011, p. 18), corroborando com o entendimento de Witkoski (2010), o comportamento voltado para a produção de excedentes nada mais é do que uma forma preventiva e compensatória encontrada pelo habitante da várzea para vencer adversidades impostas pelo ambiente, principalmente em anos de cheia e seca irregulares, quando os produtos da terra e das águas escasseiam. Em momentos de fartura, o habitante garante estoques de produtos que funcionem como uma espécie de "reserva de valor", por exemplo, milho, mandioca, gado etc., o que proporcionará o sustento da família, durante a penúria da escassez por meio de trocas, em vezes, feita com grupos sociais com 
que não possuem nenhum tipo de identificação, ou seja, mais uma vez vemos que fluxos interferem no fixo, ou melhor, relações de troca entre diversos pontos do espaço, entre diversos lugares.

Fatores externos interferem a produção local, possibilidades que independem da comunidade, mas que podem motivá-la ou desmotivá-la. Fluxos agem nos fixos e fixos respondem aos fluxos. O produtor, para produzir, utilizase de fixos, tanto para o plantio como para a colheita: terra, ferramentas e demais insumos de produção. Após a colheita chega o momento da distribuição, quando, para esta tarefa, são utilizados o rio e o barco. Rio e barco são fixos na paisagem da várzea. O rio é um objeto natural (fixo), além de ser caminho de comunicação entre as comunidades (fluxos). O barco é um objeto artificial (fixo) e um engenho do empirismo humano, que é influenciado por diversos saberes (fluxo), ele transporta produtos, pessoas e informações (fluxo). Juntos, barco e rio tornam-se agentes de circulação na distribuição de produtos e informações, alternando-se entre fixos e fluxos.

No período da cheia, a terra (fixo) desaparece e dá lugar ao espelho d'água que aos poucos transporta mecanicamente os sedimentos que nutrirão o solo (fluxo). A palafita e a terra onde a construção está erguida (fixos), muitas vezes sofrem demasiadamente com as intempéries da repetição do regime das águas, a madeira que desgasta e a terra que erode (fixos), obrigam o morador a migrar para lugares mais distantes da margem (fluxo). Quando a casa está construída em cima de um flutuante (fixo), este é levado, como que um barco, para onde as necessidades do núcleo familiar possam ser satisfeitas (fluxo). A terra que era locus de trabalho na agricultura (fixo), dá lugar à água, que é utilizada para a pesca, um lugar de trabalho que não é único, pois o homem vai onde o peixe está (fluxo), neste momento torna-se um trabalhador nômade, seja na água ou no extrativismo em terra. A enxada, a foice, o facão e demais instrumentos utilizados na terra (fixos), dão lugar aos instrumentos de pesca: caniço, rede, tarrafa, arpão (fixos), entre outros instrumentos de trabalho, na coleta e extração de produtos da floresta.

Outra maneira de identificar os fixos e os fluxos no ambiente anfíbio da várzea se dá por meio dos instrumentos engenhados para o suporte da habitabilidade no lugar, o que Santos (1988, p. 89) chama de "próteses de trabalho". O trabalhador ribeirinho apreende com poucos meios, aperfeiçoando a natureza ao seu cotidiano, o que Santos (1988) chama de "sistemas de engenharia". Este sistema de engenharia é um híbrido de fixos e fluxos. As ferramentas de trabalho em si, como já dito anteriormente, são fixos, mas as técnicas utilizadas são resultado de fluxos, dito de outra forma, são reflexo de interações e trocas experienciais que possibilitam sua construção ou adaptabilidade ao ambiente. 
A canoa, uma embarcação típica dos espaços ribeirinhos é mais um dos exemplos desta típica adaptabilidade na várzea. A embarcação é utilizada no transporte de pessoas e produtos, como principal instrumento de comunicação entre as diversas comunidades. A canoa em si é um fixo, um objeto utilizado para o trabalho, para as viagens e para o lazer do caboclo-ribeirinho. Contudo, a canoa foi adaptada, visando poupar a energia humana, utilizando-se tecnologias mais apuradas, o que resultou na adequação do "motor rabeta", garantindo, assim, a elevação de status da embarcação à catraia. Observa-se aqui a ação das tecnologias de outros lugares na várzea. O combustível da canoa que era a força humana dá lugar à gasolina ou ao óleo diesel como propulsor. A paisagem, o espaço e o lugar da várzea passam a contar com outras variáveis agindo sobre o cotidiano do lugar: a indústria petrolífera e a tecnologia das grandes indústrias navais, fluxos técnico-informacionais que pelas redes de circulação fluem aos mais distantes lugares da Amazônia.

A Assistência Técnica e Extensão Rural (ATER), política pública adotada pelo governo e muito difundida nos espaços rurais desde meados do século passado, pode ser comparada a uma espécie de "escola" de pescadores, extrativistas e agricultores. O serviço técnico prestado transmite práticas ditas mais "eficientes" para o cultivo, para a criação e para a coleta extrativista nos ambientes rurais, possibilitando, às vezes, linhas de financiamento para os diversos tipos de atividades. Podemos observar que esta política é uma espécie de fluxo, que congrega princípios de planejamento, gestão, beneficiamento e comercialização, aliando ciência, conhecimentos tradicionais e alternativas econômicas, ou seja, as políticas de ATER influenciam a organização social do lugar e metamorfoseia o espaço, seja pela organização social, pela política, pela economia ou pela cultura.

Encontramos nos espaços de várzea fixos e fluxos, objetos que horas são fixos e hora são fluxos, característica que demonstra como os lugares e os espaços estão em constante movimento, garantindo assim a reprodução da organização social camponesa ribeirinha.

\section{CONSIDERAÇÕES FINAIS}

Embora as características da vida ribeirinha sejam basicamente as mesmas de quando houve a primeira expansão da colonização europeia na Amazônia - apoiada na organização familiar, voltada a produzir para a subsistência e para a geração de excedentes que garantam a manutenção da vida em períodos de escassez, o espaço e o lugar de outrora mudaram bastante, assim como as paisagens. 
A inauguração da navegação nas águas do "grande rio" trouxe uma série de interferências nos padrões de organização da vida econômica e social das comunidades. Percebe-se claramente, pela rede de intercâmbios de energia e de informações da bacia amazônica, que as trocas de experiências entre os diversos lugares são diversas, o que motivou Tocantins (1973, p. 278) a afirmar que "o sistema hidrográfico do rio Amazonas tem caráter eminentemente social", ou seja, o movimento das águas determina a organização social das comunidades, ou melhor, os rios exercem poder social sobre a vida humana.

A forma com que os homens anfíbios, apresentados por Fraxe (2000), adequam-se a ambientes de terra e águas para retirar os meios de subsistência, revela-nos o poder social que o rio e seu regime exerce sobre o varziano. Todavia, não podemos falar em isolamento dessas comunidades, uma vez que estes lugares experimentam todos os tipos de relações e intercâmbios sociais com outras formas de organização social, política ou cultural, por meio dos fluxos que Santos (1988) problematizou.

Enfim, a dinâmica social, econômica e ambiental da várzea garante aos lugares e aos espaços um constante movimento, produzindo e reproduzindo o modo de vida e a organização social, espaços onde são satisfeitas as necessidades a partir da experiência do lugar.

\section{REFERÊNCIAS}

BRASIL. Ministério do Meio Ambiente. Resolução nº 004/1985 - CONAMA. Brasília, 1985. Disponível em: < http://www.mma.gov.br/conama/>. Acesso em: 13 jan. 2012.

COLLYER, F. Crônicas da história do Amazonas. 2. ed. Manaus: Editora K, 1999.

FRAXE, T. de J. P. Cultura cabocla-ribeirinha: mitos, lendas e transculturalidade. São Paulo: Annablume, 2005.

Homens anfíbios: etnografia de um campesinato das águas. São Paulo: Annablume, 2000.

GIDDENS, A. As consequências da modernidade. Tradução de Raul Fiker. São Paulo: UNESP, 1991.

GIUCCI, Guilhermo. Frei Gaspar de Carvajal. Edição Bilíngue. Traduzido por Adja Balbino Barbieri Durão. São Paulo: Scritta, 1992. (Coleção Orellana). 
IBAMA. A posse da terra no ambiente de várzea: debates para uma possível solução. Manaus: IBAMA/ProVárzea, 2005. (Coleção Cartilha Estudos Estratégicos)

MARX, K. O Capital: crítica da economia política. Traduzido por Regis Barbosa e Flávio R. Kothe. 3. ed. São Paulo: Nova Cultural, 1988. (Coleção Os economistas).

NOGUEIRA. R. J. B. Amazonas: um estado ribeirinho. Manaus: EDUA, 1999.

PEREIRA, H. dos S. A dinâmica da paisagem socioambiental das várzeas do rio Solimões-Amazonas. In: FRAXE, T. J. P.; PEREIRA, H. S.; WITKOSKI, A. C. (Orgs.). Comunidades ribeirinhas amazônicas: modos de vida e uso dos recursos naturais. Manaus: Rego Edições, 2011.

PIRES, G. A. Áreas úmidas e patrimônio natural: uma visão estratégica para a água em espaços transfronteiriços? Novos Cadernos NAEA. Belém, v. 14, n. 1, p. $97-114,2011$.

SANTOS, M. A natureza do espaço: técnica e tempo, razão e emoção. 4. ed. 5. reimp. São Paulo: USP, 2009.

Metamorfoses do espaço habitado. 5. ed. São Paulo: HUCITEC, 1997.

SILVA, M. C. da. As metamorfoses da Amazônia. Manaus: EDUA, 2000.

STERNERG, H. O’R. A água e o homem na várzea do Careiro. 2. ed. Belém: MPEG, 1998.

SURGIK, A. C. Estudo jurídico para a várzea amazônica. In: BENATTI, J. H. et al. A questão fundiária e o manejo dos recursos naturais da várzea: análise para a elaboração de novos modelos jurídicos. Manaus: IBAMA/ProVárzea, 2005. p. $15-32$

TOCANTINS, L. O rio comanda a vida: uma interpretação da Amazônia. Rio de Janeiro: Biblioteca do Exército, 1973.

TUAN, Y.-F. Espaço e lugar: a perspectiva da experiência. Tradução de Lívia de Oliveira. São Paulo: Difel, 1983.

WITKOSKI, A. C. Terras, florestas e águas de trabalho: os camponeses amazônicos e as formas de uso de seus recursos naturais. São Paulo: Annablume, 2010 . 